\title{
O PROCESSO DE EDUCAÇÃO EM SAÚDE PARA ALÉM DO HEGEMÔNICO NA PRÁTICA DOCENTE
}

\author{
Rosane Teresinha Fontana ${ }^{1}$
}

\section{RESUMO}

Trata-se de uma revisão narrativa que tem como objetivo propor uma reflexão sobre o processo de Educação em Saúde na prática docente, visto que a legislação brasileira orienta sobre a inserção deste tema na escola. Desenvolver atividades de Educação em Saúde que potencializem a capacidade do estudante de decidir sobre quais as estratégias mais apropriadas para promover, manter e recuperar sua saúde, considerando seus saberes e sua autonomia, pode agregar valor ao processo, na medida em que dialoga, responsabiliza, enaltece a importância da vida e tem potencial para operar sobre os determinantes sociais de saúde que causam sofrimento e adoecimento. É preciso refletir sobre possibilidades que congreguem saber, cidadania e coletivo à promoção da saúde, construindo-se relações e práticas educativas alicerçadas na mútua responsabilidade e na horizontalidade no cuidado à saúde.

Palavras-chave: Educação em Saúde. Prática docente. Promoção da saúde.

\section{THE PROCESS OF HEALTH EDUCATION BEYOND HEGEMONICS IN TEACHING PRACTICE}

\section{ABSTRACT}

This a narrative review aims to propose a reflection on the process of Health Education in the teaching practice, given that Brazilian legislation guides the insertion of this theme in school. Developing Health Education activities that enhance students' ability to decide on the most appropriate strategies to promote, maintain and recover their health, considering their knowledge and autonomy, can add value to the process, as it dialogues, blame and praises the importance of life and has the potential to operate on the social determinants of health that cause suffering and illness. It is necessary to reflect on possibilities that bring knowledge, citizenship and collective to the promotion of health, building relationships and educational practices based on mutual responsibility and horizontality in health care.

Keywords: Health Education. Teaching practice. Health promotion.

RECEBIDO EM: $16 / 1 / 2018$

ACEITO EM: 3/6/2018 


\section{CONSIDERAÇÕES INICIAIS}

Este estudo propõe uma reflexão sobre o processo de educação em saúde na prática docente. O Ministério da Saúde define Educação em Saúde como um processo educativo de construção de conhecimentos em saúde com vistas à apropriação pela população. Trata-se de um "conjunto de práticas que contribui para aumentar a autonomia das pessoas no seu cuidado e no debate com os profissionais e os gestores a fim de alcançar uma atenção de saúde de acordo com suas necessidades" (BRASIL, 2009, p. 22).

Diante desse conceito, pretende-se discutir a Educação em Saúde, não pelo viés da simples informação ou prescrição do saber técnico-científico profissional, características da educação bancária e higienista. Busca-se refletir sobre uma prática educativa emancipatória, que transforma saberes existentes, no intuito de fomentar o desenvolvimento da autonomia e da responsabilidade dos indivíduos no cuidado com a saúde, num movimento que leve a pessoa a refletir e compreender a situação de saúde individual e coletiva, mediante comunicação dialógica que "capacite os indivíduos a decidirem quais as estratégias mais apropriadas para promover, manter e recuperar sua saúde" (SOUZA; JACOBINA, 2009, p. 624).

Trata-se de uma reflexão que utilizou a revisão narrativa como método. Os estudos que realizam revisões de literatura e de produções científicas têm várias denominações, tais como revisão integrativa, sistemática, bibliográfica, e, entre tantas outras, a revisão narrativa, que permite estabelecer relações com produções anteriores, identificando temáticas recorrentes, apontando novas perspectivas, consolidando uma área de conhecimento e construindo orientações de práticas pedagógicas para a formação de profissionais (ROCHA, 1999; VOSGERAU; ROMANOWSKI, 2014). A revisão narrativa possibilita a realização de análises e interpretações amplas, de modo a compreender o "estado da arte" do assunto, sob um ponto de vista teórico ou contextual (ELIAS et al., 2012), com possibilidade de contribuir com a teoria e com a prática de uma área do conhecimento (MESSINA,1998). Nesta metodologia descreve-se o "estado da arte" sem utilizar critérios sistemáticos para a busca e análise crítica da literatura e a seleção dos estudos, e a interpretação das informações podem estar sujeitas à subjetividade dos autores (UNIVERSIDADE..., 2015).

O artigo 70 da lei 5.692/71 legisla sobre a obrigatoriedade da inserção da Educação em Saúde nos processos de ensino e aprendizagem no Brasil, com o intuito de estimular o conhecimento e a prática da saúde básica (MOHR; SCHALL, 1992). Nos Parâmetros Curriculares Nacionais (PCNs), em seus Temas Transversais, está citado que a saúde deve ser abordada em todas as áreas do conhecimento (BRASIL, 1997), de forma transversal a todas as disciplinas por meio da articulação de projetos e planejamentos interdisciplinares de conteúdos relacionados tanto à saúde individual quanto coletiva.

O que se observa empiricamente nas escolas, porém, é que nem todos os(as) profissionais da educação estão preparados para o desenvolvimento desse tema em seus planejamentos, e, se o fazem, o abordam no viés biomédico, focado na doença. A Educação em Saúde, no entanto, é uma demanda real do ambiente escolar e não pode ser desenvolvida a partir de concepções baseadas no senso comum e/ou alicerçadas em intenções sanitaristas, higienistas (GUSTAVO; GALIETA, 2014, p. 3). 
Estudo desenvolvido com professores(as) de Ensino Médio apontou que a concepção sobre saúde por parte dessas pessoas é limitada e que o tema é abordado em sala de aula com a única finalidade de prevenir doenças, atrelado ao modelo de saúde biomédico focado no patológico, dados que podem ser justificados pela deficiência de cursos de formação continuada sobre a temática, numa perspectiva contemporânea; apenas $25 \%$ dos(das) professores(as) entrevistados(as) afirmaram ter participado de algum curso de formação continuada sobre o tema saúde (SILVA et al., 2017).

Abordar o tema da saúde numa perspectiva contemporânea envolve desprender-se do conceito reducionista de que saúde é, simplesmente, ausência de doença. A Educação em Saúde deve estar implicada num movimento maior, de promoção da saúde. Por força hegemônica do modelo biomédico, compreende-se por que, para a maioria da população, saúde é não estar doente, embora esta definição seja muito limitada, ao considerar que nem sempre a ausência de sinais e sintomas indica que o indivíduo encontra-se numa condição saudável. Muitas pessoas consideram-se normais, mesmo que portadores de uma determinada doença (BATISTELLA, 2007).

Além disso, em muitos cenários escolares, a abordagem do tema saúde no escolar é orientada unicamente às disciplinas de Ciências e Biologia. Esta situação não constitui, por si só, uma redução do tema saúde, mas o viés de abordagem é, quase sempre, responsável por dar conta dos determinantes biomédicos que interferem sobre a saúde e,

a ação de redução é consumada quando o tema saúde é tratado exclusivamente pelo viés biomédico, ou por qualquer outra forma que valorize uma única ótica de abordagem em detrimento de outras. Tratar o tema saúde de maneira a dar exclusividade a um viés de abordagem implica diretamente na negação da influência de outros determinantes que atuam mutuamente sobre o estado de saúde (GUSTAVO; GALIETA, 2014, p. 3).

Diante disso, é válida uma reflexão sobre as concepções que envolvem a Educação em Saúde de modo a fornecer elementos para a prática e, especialmente, para a formação de professores(as), visto que "o desconhecimento dos(as) professores(as) em geral, sobre as questões mais básicas 'da saúde' se enraíza no processo de formação inicial e se alonga na formação continuada" (LIMA; MALACARNE; STRIEDER, 2012, p. 201).

Muitos(as) autores(as) têm debatido o conceito de saúde como mera ausência de doença. Para Almeida Filho (2011, p. 54, 69), do ponto de vista rigorosamente clínico, saúde "não seria oposto lógico da doença, por isso, estado de saúde não poderia de modo algum ser definido como 'ausência de doença'". Estado de saúde "difere de patologia, fator de risco ou etiologia; é um atributo multidimensional dos seres humanos [...] os estados individuais de saúde não são excludentes vis-à-vis a ocorrência de doença".

Após muitos debates em torno das concepções que pudessem abarcar completamente a condição saudável, a Organização Mundial da Saúde (OMS), em 1948, define saúde como um completo estado de bem-estar físico, mental e social, e não apenas a ausência de doença ou enfermidade, conceito que também é criticado, haja vista seu caráter utópico, inalcançável. A expressão "completo estado" indica uma concepção pouco dinâmica do processo; as pessoas não permanecem constantemente em estado de bem-estar. O conceito revela, ainda, que, sendo inatingível, haveria dificuldades dos sistemas de saúde em usá-lo como meta. Além disso, carece de objetividade. Alicerçado 
em uma noção subjetiva de "bem-estar", implicaria a impossibilidade de medir o nível de saúde de uma população. E a simples tentativa de definir o estado de bem-estar mental e social poderá "supor uma existência sem angústias ou conflitos, sabidamente inerentes à própria história de cada ser humano e de cada sociedade" (BATISTELLA, 2007, p. 58).

É oportuna, porém, uma consideração, visto que, diante desse conceito da OMS, a saúde passa a ser mais um valor social do que individual, sendo, portanto, um valor coletivo, um bem de todos, devendo cada um gozá-la, sem prejuízo do outro, e, solidariamente, com todos.

A "saúde social" traduz-se na alegria de viver, no bem-estar físico, psíquico e econômico do indivíduo, relacionado a sua família e ao meio em que vive [...]. O que expressa a "saúde social" é o comportamento ajustado do indivíduo dentro da comunidade; é a aceitação e o exercício corretos dos padrões de vida adotados por esta; é a eficiência do regulador, do legislador e sobretudo do político [...] que esteja bem integrado na ordem e no esforço organizado da comunidade, sinta a necessidade de resolver os problemas fundamentais do seu povo; é a participação inteligente e interessada no bem-estar físico-social e psíquico, procurando encontrar soluções para as necessidades sociais, de todos os cidadãos; é manter boas relações humanas; é ser livre; é ser feliz; é ser consciente de suas responsabilidades; é sentir a necessidade de governar bem, legislar bem e regular bem (ORGANIZAÇÃO..., 2016).

Em 1986 a 8a Conferência Nacional de Saúde debateu o "conceito ampliado" de saúde, ou seja, a saúde é resultante das condições de alimentação, habitação, educação, renda, meio ambiente, trabalho, transporte, emprego, lazer, liberdade, acesso e posse da terra e acesso aos serviços de saúde. É, principalmente, resultado das formas de organização social, de produção, e que podem gerar grandes desigualdades nos níveis de vida (BRASIL, 1986).

Diante dessas discussões, e sabendo-se que alguns grupos da população são mais saudáveis que outros, e que é possível identificar desigualdades decorrentes das condições sociais em que as pessoas vivem e trabalham, as que são injustas e inaceitáveis são denominadas iniquidades (BRASIL, 2006), surge um movimento que discute os fatores determinantes e condicionantes de saúde. Exemplo disso é a probabilidade cinco vezes maior de uma criança morrer antes de alcançar o primeiro ano de vida pelo fato de ter nascido no Nordeste e não no Sudeste (BATISTELLA, 2007).

Outro exemplo é a chance três vezes maior de uma criança morrer antes de chegar aos 5 anos de idade pelo fato de sua mãe ter 4 anos de estudo e não 8 e mais um exemplo que pode ilustrar essa condição é a tuberculose. $O$ bacilo de Koch é um microrganismo que causa a tuberculose, mas são os determinantes sociais que explicam porque determinados grupos da população são mais suscetíveis do que outros para contrair a tuberculose (BATISTELLA, 2007). Daí a denominação de "determinantes sociais da saúde" (BRASIL, 2006). 
Pela sua complexidade, "a saúde deve ser compreendida em seus múltiplos aspectos. Ela nunca será redutível a qualquer de suas dimensões, seja ela biológica, psicológica, individual ou coletiva, objetiva ou subjetiva" [...] e seu estudo exige construtos "não mais referenciados à epistemologia positivista, analítica, e sim a partir de uma perspectiva transdisciplinar, totalizante" (BATISTELLA, 2007, p. 79).

\section{A EDUCAÇÃO EM SAÚDE NA PRÁTICA DOCENTE}

Muitas variáveis são responsáveis pelo fracasso escolar. As extraescolares são, entre outras, as condições precárias de alimentação, habitação e saneamento básico, determinantes sociais que afetam a saúde da criança, do adolescente e do jovem. As variáveis intraescolares relacionam-se ao currículo, aos programas, ao trabalho do professor e às avaliações de desempenho. Tudo isso contribui para o fracasso escolar dos estudantes de origem social e econômica desfavorecidas. Buscar soluções para o fracasso escolar não consiste em atribuir patologias à pessoa, nem na medicalização, mas em ampliar espaços para a visibilidade de outras variáveis que influenciam no processo da aprendizagem, tais como a instituição, o método de ensino, as relações entre o professor e o estudante, os aspectos socioculturais, a história de vida dos envolvidos (MOTA et al., 2008).

A medicalização, referendada apenas ao saber médico, não resolve os problemas de aprendizagem enfrentados pelas escolas, porém sabe-se que esta prática advém do pensamento dominante dos séculos 19 e 20. Mudanças nas estruturas sociais, econômicas e políticas, tais como a abolição da escravatura, a saída dos trabalhadores do campo para as cidades ainda deficientes em infraestrutura e de crescimento desordenado, 0 desenvolvimento do comércio e da indústria, as precárias condições de transporte, saneamento e higiene com lugares e moradias insalubres, trouxeram como consequências condições sanitárias ameaçadoras e surtos epidêmicos que inquietavam as classes dirigentes, tais como o aparecimento e a propagação de doenças como varíola, febre amarela, tuberculose e cólera, que assolavam os núcleos urbanos e começavam a ameaçar a força de trabalho, que, por consequência, prejudicavam as atividades capitalistas. Era necessário que se estabelecessem medidas urgentes, visto que a saúde era valorada pelo potencial da força de trabalho necessária e requerida pela indústria e seus meios de produção (SOUZA; JACOBINA, 2009). A ideologia de práticas higienistas era associada à formação de jovens saudáveis para o mercado produtivo que a sociedade mercantilista exigia.

No quadro da evolução histórica verifica-se uma tentativa de manter na escola uma proposta de ações sanitárias de cunho higienista, biologicista e curativo, desenhadas por vigilância e controle da higienização do ambiente escolar, prevenção de acidentes, curativos a pequenos ferimentos, distribuição de anti-helmínticos, antianêmicos, analgésicos, palestras, etc. Em 1924 o médico Carlos Sá constituía no Rio de Janeiro os "pelotões da saúde", aglomerações de estudantes que seguiam regras para a saúde, inclusive morais, com disciplina militar. Foi a "Higiene Escolar", calcada no modelo alemão de "Polícia Médica", que originou a saúde escolar. Para reorganizar e reformar a sociedade, a proposta tinha como base um modelo de saúde na escola, calcado em princípios higienistas e eugênicos" (SILVA; BODSTEIN, 2016, p. 1.778) 
Reitera-se a urgência em discutir em todos os segmentos a relação entre saúde e determinantes sociais. Ao invés da ênfase exclusiva nos fatores e nas características biológicas, a saúde deve ser compreendida como produto da vida cotidiana, que considera-aspectos socioculturais ligados às condições de vida. Esse debate ganha força e reconhecimento no Brasil e reafirma a escola como espaço relevante para construção de cenários mais favoráveis à vida com qualidade (SILVA; BODSTEIN, 2016).

A partir dessas reflexões pode-se inferir que a prática educativa em saúde se expande e ultrapassa a relação de ensino e aprendizagem didatizada e assimétrica; transpõe o simples cultivo de hábitos saudáveis e passa a congregar a concepção de intencionalidade, focada num projeto de sociedade. Deverá ser construída tendo como ponto de partida as situações de saúde de um grupo social, constituindo-se como um processo em que a relação entre os envolvidos seja dialógica e horizontal. A Educação em Saúde deve ser considerada uma prática social, cujo processo contribui para a sensibilização e formação da consciência crítica das pessoas a respeito de seus problemas de saúde, para, diante da sua realidade, discutir coletivamente, na busca de soluções.

Capacitações teóricas, contudo, que se utilizam somente de palestras e conferências, são estratégias não tão seguras para a Educação em Saúde para as pessoas. Em muitas situações e em muitos cenários de ensino e Educação em Saúde há necessidade de atitudes dinâmicas e de metodologias ativas que possam envolver os atores de forma significativa e implicada com o compromisso social (WEGNER et al., 2016).

Para Bastos (2006), o conceito de metodologias ativas envolve um "processo interativo de conhecimento, análise, estudos, pesquisas e decisões individuais ou coletivas, com a finalidade de encontrar soluções para um problema", no qual o docente deve atuar como um facilitador, para que o aluno pesquise, reflita e decida por ele mesmo o que fazer para alcançar os objetivos. Entre as diversas metodologias existentes e utilizadas como recurso didático e pedagógico para formação crítica do estudante merecem destaque o método "Problem Based Learning" (PBL) ou aprendizagem baseada em problemas, e os Grupos Operatórios. O primeiro envolve um método caracterizado pelo uso de problemas do mundo real para encorajar os estudantes a desenvolverem pensamento crítico e habilidades de solução de problemas e o segundo um processo ativo de troca e produção de conhecimento, e não somente difusão de informações (BORGES; ALENCAR, 2014).

Além disso, não podem ser negligenciadas neste processo a facilidade de acesso à informação que a Internet propicia e a imensa disponibilidade de recursos digitais que configuram um novo perfil de discentes, os nativos digitais, com necessidade de respostas rápidas aos seus questionamentos e expectativa de que a tecnologia faça parte do ambiente escolar. "A diversificação no uso de diferentes recursos tecnológicos proporciona o aprendizado a partir da mobilização das múltiplas potencialidades, capacidades e interesses dos educandos. Favorece a construção do aprendizado coletivo, de maneira colaborativa [...]" (MARUXO et al., 2015, p. 72).

Metodologias inovadoras de ensino, interconectadas às tecnologias também inovadoras podem ser utilizadas como instrumentos/recursos para a conquista de saberes, habilidades e competências. 
Refletir sobre a Educação em Saúde pode contribuir para ressignificar o seu sentido na prática docente. Ao longo da história da saúde coletiva, diferentes paradigmas de Educação em Saúde foram construídos, alicerçados por variadas estratégias, muitas delas positivistas e autoritárias, do tipo "um ensina e o outro aprende". É a partir desta acepção que emergiu a motivação para problematizar a Educação em Saúde na prática docente na contemporaneidade. É válido sublinhar que a configuração social do Brasil exige que se transforme a Educação em Saúde em espaços de integração e participação, como um trabalho coletivo de empoderamento de estudantes e professores(as), alinhavada entre os saberes científicos, populares e, na sua fusão, emergir um terceiro saber que possa ser um multiplicador de ações promotoras de saúde.

A escola é um importante espaço para o desenvolvimento de um programa de educação para a saúde. Distingue-se das demais instituições por oferecer a possibilidade de educar por meio da construção de conhecimentos resultantes da discussão dos diversos saberes, sejam os trazidos pelos conhecimentos científicos trabalhados pelas diferentes disciplinas; aqueles trazidos pelos estudantes que expressam crenças e valores culturais; os divulgados pelos meios de comunicação, às vezes fragmentados e desconexos, mas que devem ser levados em conta por exercerem forte influência sociocultural e aqueles trazidos pelos(as) professores(as), decorrentes da sua experiência, de vivências pessoais e profissionais, que envolvem crenças e se expressam em atitudes e comportamentos. Esse encontro de saberes gera a "cultura escolar", que assume expressão própria e particular em cada instituição, embora apresente características comuns ao que é típico do contexto escolar (BRASIL, 2009).

A Educação em Saúde pode configurar-se como um sistema fundamentado na participação das pessoas, visando à transformação social, rompendo com o paradigma da concepção estática de educação como transferência de conhecimentos, habilidades e destrezas (BRASIL, 2007a). A fim de afastar-se da visão prescritivista e autoritária da ciência, a ação pedagógica docente deste tema nas escolas deve, pois, estabelecer uma relação de aprendizado partilhado, de mútua busca do saber. Não se trata de buscar comportamentos não saudáveis ou de risco, mas identificar e compreender as razões das vulnerabilidades coletivas.

Todos aprendem com os moradores mais antigos, as origens, as características que mudaram e as que permaneceram.

Com os artistas, a linguagem, os desejos e os significados culturais; com os professores, a realidade das escolas; com os moradores, o grau de satisfação com os serviços e as percepções diferenciadas sobre os problemas; com os epidemiólogos, as informações sobre as tendências e o perfil de saúde e doença; com os ACS, as singularidades e capacidades da população. Dependendo do problema identificado, novos olhares são requisitados, e assim podem-se encontrar formas de viabilizar aquilo que todo ano, passivamente, repete-se como mera queixa sem comprometimento algum com a mudança (BATISTELLA, 2007, p. 81-82).

A escola tem potencial para educar para a saúde a partir da dialogicidade, do lúdico, da livre-expressão, num movimento dialógico que propõe a construção do conhecimento pela conversação, pelo respeito às ideias e saberes, em que educador e educando sejam protagonistas do processo de aprendizagem, ambos utilizando sua bagagem 
crítico-reflexiva da realidade (SANTOS; FONTANA; BRUM, 2013). Neste sentido, um estudo (LEITE et al., 2014) demonstrou que, quanto à escolha dos temas abordados para as atividades educativas em saúde, $43 \%$ dos participantes mencionaram que os profissionais da saúde ou da educação não os consultaram para conhecer suas opiniões e necessidades. Entre os profissionais que realizaram as ações educativas em saúde, 35,2\% citaram que essas atividades foram desenvolvidas por professores(as) das próprias escolas, contra $64,8 \%$ por profissionais de saúde, resultados que demonstram a participação ainda tímida dos primeiros neste processo.

O ser humano deve ser visto como uma pessoa incluída em contextos socio-econômico, físico, político e cultural. Sem a percepção dessa dimensão, torna-se inimaginável prevenir e promover a saúde coletiva ou individual, numa comunidade ou de uma pessoa. Com o incentivo à curiosidade, que pode se transformar em questionamento, a problematização da realidade se compõe e se recompõe, resultando, pois, na reflexão crítica e contribui para que a pessoa seja capaz de entender, analisar e enfrentar a realidade, transformando-a. As ações educativas para serem efetivas devem evitar visões simplistas e limitadas de formação de cidadãos. Formar, nessa concepção, implica moldagem, de massa amorfa capaz de se transformar somente por meio de informações, conteúdos e teorias, como algo externo ao sujeito (SHIRATORI et al., 2004).

Neste sentido, pode-se apontar a pedagogia freiriana, que conforme Morosini, Fonseca e Pereira (2009), concebe o processo ensino-aprendizagem como uma troca, um processo dialógico entre educador e educando, que ocorre numa realidade vivida.

O conhecimento advém da reflexão crítica sobre essa realidade, construindo-se, ao mesmo tempo em que o homem vai se constituindo e se posicionando como um ser histórico. [...] não cabem relações verticais entre educador e educando, ou a transferência de conhecimentos e a normatização de hábitos, que marcaram o pensamento hegemônico da educação sanitária no século passado e que ainda hoje estão presentes nas práticas educativas em saúde (MOROSINI; FONSECA; PEREIRA, 2009, p. 1).

Assim, é oportuno refletir sobre os construtos pedagógicos que estão implicados com a Educação em Saúde. As concepções ou abordagens pedagógicas tradicionais são aquelas em que o processo educativo é centrado em alguém que sabe e ensina a alguém que não sabe, numa concepção de transmissão de conhecimentos e de "condicionamento", concentrando-se no modelo de estímulo e recompensas capaz de "condicionar" o aprendiz a emitir as respostas desejadas. Já as concepções ou abordagens pedagógicas que têm o aprendiz como foco envolvem a "Humanista", a "Cognitivista" e a "Sociocultural". A primeira privilegia os aspectos da personalidade do sujeito que aprende. Corresponde ao "ensino centrado no estudante"; a segunda investiga os caminhos percorridos pela inteligência no processo de construção do conhecimento e a terceira coloca no centro do processo de ensino-aprendizagem os contextos político, econômico, social e cultural nos quais ocorre a ação educativa (MACHADO; WANDERLEY, 2017).

Nesta dialética, as metodologias ativas podem contribuir para dinamizar o processo. Para ilustrar, um estudo desenvolvido por Maia et al. (2012), que teve como objetivo descrever a validação de metodologias ativas de Educação em Saúde, na promoção da 
alimentação saudável de crianças do Ensino Fundamental, por meio de recursos lúdicos, identificou que algumas técnicas foram muito eficazes para a educação em saúde alimentar. Foram usadas metodologias, tais como dinâmicas de avaliação, minuto-cinema, momento-teatro e caixa dos sentidos para o desenvolvimento da proposta.

Os autores enfatizaram a importância do lúdico, audiovisual, o uso de cores para estimular a compreensão do preparo, a quantidade certa a ser ingerida e local adequado para realizar as refeições, fatores esses que são de vital importância para a qualidade de vida dessas crianças. A dinâmica de avaliação foi feita a partir da colagem de figuras de alimentos em dois painéis: o primeiro deles destinado à colagem de figuras de alimentos saudáveis, e o segundo, de alimentos inadequados à saúde. Do total de 25 crianças, $84 \%$ efetivaram a colagem adequada dos alimentos.

O minuto-cinema desenvolveu-se por meio de reunião das crianças em um auditório, para apresentação de um vídeo sobre o valor nutricional das frutas e verduras para o adequado desenvolvimento infantil, por meio de canções. A dinâmica da caixa dos sentidos envolveu a colocação de frutas e verduras numa urna. Participantes foram estimulados, por meio do sentido tátil, a descobrir o alimento e no final da dinâmica discorreu-se sobre o seu valor nutricional na alimentação. No momento-teatro a proposta foi a redução do consumo de guloseimas, presentes no cenário de "Joãozinho e Maria", bem como a elevação da ingesta de nutrientes favoráveis a um desenvolvimento cognitivo satisfatório (MAIA et al., 2012).

Também é possível a construção de um saber coletivo, em formato de círculo, os chamados "Círculo de Cultura", os quais possibilitam o encontro do pessoal, do formal e do informal. Brandão (2010, p. 69) refere que no círculo de cultura o diálogo deixa de ser uma simples metodologia ou uma técnica de ação grupal e passa a ser a própria diretriz de uma experiência didática centrada no pressuposto de que "aprender é aprender a dizer a sua palavra".

Oportunizar espaços de reflexão entre as pessoas envolvidas no processo de educação em saúde pode facilitar e promover a ressignificação de suas vivências para a transformação da realidade social, por meio da concretização de ações locais de vigilância sanitária, que possam efetivamente intervir na prevenção de agravos à saúde coletiva e individual. Esse foi o objetivo de uma experiência de atualização de professores(as) de Ciências da rede estadual de ensino de um município do interior do Estado do Rio Grande do Sul (BR), sobre ações de vigilância sanitária e a interface com os Parâmetros Curriculares Nacionais (FONTANA, 2008).

Após um momento de troca de saberes entre a facilitadora e os(as) professores(as), foram realizadas oficinas em pequenos grupos para que as reflexões, ideias e questionamentos fossem socializados ao grande grupo, a fim de subsidiar alternativas de ações educativas a cada docente no seu local de trabalho. Num segundo momento e a partir dos encontros presenciais com os(as) professores(as), foi-lhes solicitada a elaboração de projetos, com a participação dos estudantes, os quais, efetivamente, pudessem melhorar as condições sanitárias da comunidade em que viviam. Num terceiro momento organizou-se uma feira aberta ao público, na qual os estudantes puderam relatar à comunidade os resultados destas ações. As atividades educativas desenvolveram-se a partir da transversalização da temática com o plano de ensino. Sendo assim, as ativida- 
des pautaram-se em ações de Educação em Saúde, que viessem ao encontro dos Parâmetros Curriculares Nacionais (PCNs), ao considerar que um dos eixos temáticos destes PCNs, na área de Ciências Biológicas, envolve o ser humano, a saúde e o ambiente,

Os projetos desenvolvidos abrangeram atividades de inspeção sanitária em pequenos supermercados e armazéns varejistas locais, observando a validade dos alimentos, a situação das embalagens, condições de armazenamento e distribuição dos produtos ao varejo; as condições de higiene dos estabelecimentos; o destino dos resíduos domésticos e sua reciclagem, com orientações à comunidade e visitas ao local de processamento dos resíduos, confecção de utilidades com papel reciclado, produção de alimentos com sementes, cascas e elaboração de manual de receitas com estes alimentos; orientação às merendeiras da escola, entre outras. Essa experiência ilustra uma atividade em que o(a) professor(a) e o(a) estudante aprendem e/ou se atualizam (FONTANA, 2008).

Estudo que ampliou reflexões para o desenvolvimento e para a reorientação de práticas em saúde que viabilizassem atuações efetivas de promoção da saúde, bem como a delegação de poder do adolescente dentro do seu papel de multiplicador, para atuar junto a seus pares, identificou, entre outros aspectos, que o papel de facilitador tem potencial para que as ações promotoras de saúde realizadas em oficinas de Educação em Saúde sejam apreendidas pelos sujeitos que, empoderados, possam sentir-se aptos a serem replicadores do saber obtido e executem ações de promoção da saúde nos contextos em que vivem (SILVA et al., 2018).

No Brasil, o Unicef organizou um conjunto de 20 competências com as quais os adolescentes podem trilhar os caminhos da cidadania de forma mais segura, cientes de seus direitos e de suas responsabilidades (UNITED..., 2012). Contam ainda com o apoio de uma rede de atores responsáveis por ajudá-los na construção de sua identidade, na conquista de sua autonomia e no seu processo de interação com outros adolescentes, crianças e adultos de referência em sua vida, promovendo o desenvolvimento integral dos jovens. Foram denominadas de Competências para a Vida (sublinha-se que são competências que podem integrar processos de Educação em Saúde para jovens). Entre outras, estão: proteger a si mesmo e os outros de vulnerabilidades; construir relações sustentáveis e de confiança; estabelecer relações interpessoais afetivas e sustentáveis; adotar atitude de respeito à diversidade e ao meio ambiente; desenvolver a comunicação interpessoal; adotar atitude saudável pela prática de esportes; proteger os outros e a si mesmo das doenças sexualmente transmissíveis e da Síndrome da Imunodeficiência Adquirida.

É oportuna, nesta reflexão, uma consideração sobre alguns Objetivos e Metas dos Indicadores da Saúde do Ministério da Saúde e Determinantes Sociais (BRASIL, 2018), que poderão constar na agenda da Educação em Saúde na escola.

O objetivo 3, Saúde e bem-estar, define, entre suas metas,

até 2030, acabar com as epidemias de Aids, tuberculose, malária e doenças tropicais negligenciadas, e combater a hepatite, doenças transmitidas pela água, e outras doenças transmissíveis [...] promover a saúde mental e o bem-estar; reforçar a prevenção e o tratamento do abuso de substâncias, incluindo o abuso de drogas entorpecentes e uso nocivo do álcool; [...] assegurar o acesso universal aos servi- 
ços de saúde sexual e reprodutiva, incluindo o planejamento familiar, informação e educação, bem como a integração da saúde reprodutiva em estratégias e programas nacionais; [...] reduzir substancialmente o número de mortes e doenças por produtos químicos perigosos e por contaminação e poluição do ar, da água e do solo; [...]controle do tabaco.

O objetivo 5, Igualdade de gênero, delibera como metas prioritárias

eliminar todas as formas de violência contra todas as mulheres e meninas nas esferas públicas e privadas, incluindo o tráfico e exploração sexual e de outros tipos e assegurar o acesso universal à saúde sexual e reprodutiva e os direitos reprodutivos, como acordado em conformidade com o Programa de Ação da Conferência Internacional sobre População e Desenvolvimento e com a Plataforma de Ação de Pequim e os documentos resultantes de suas conferências de revisão.

O Objetivo 16, Paz, justiça e instituições eficazes, determina como metas principais "reduzir todas as formas de violência e as taxas de mortalidade relacionadas, em todos os lugares; acabar com abuso, exploração, tráfico e todas as formas de violência e tortura contra crianças".

A Educação em Saúde realizada, seja por professores(as) ou por profissionais de saúde, deve ter o intuito de garantir a dignidade da pessoa por meio da promoção da saúde, representando "uma forma de objetivação dos direitos humanos fundamentais, visto que estes se manifestam na autodeterminação consciente e responsável da própria vida" (SHIRATORI et al., 2004, p. 618). Deve proporcionar às pessoas não só conhecimentos sobre novos hábitos e condutas de saúde, para a prevenção de agravos, mas também sobre ações de autocuidado, de participação popular nos serviços de saúde, de formação crítica-cidadã, por meio de atitudes emancipadoras para a promoção da saúde. Requer a escuta ativa e o diálogo aberto, construindo relações horizontais, facilitadoras, e não, meramente, a compreensão da informação, e que incentivem as pessoas a resolver os seus próprios problemas, encontrar as soluções e lidar com eles de forma eficaz (FONTANA; BRUM, 2014), atentas à promoção da saúde e à prevenção de agravos que expõem grupos vulneráveis.

A estratégia de promoção da saúde é retomada como uma possibilidade de enfocar os aspectos que determinam o processo saúde-adoecimento em nosso país, como: violência, desemprego, subemprego, falta de saneamento básico, habitação inadequada e/ou ausente, dificuldade de acesso à educação, fome, urbanização desordenada, qualidade do ar e da água ameaçada e deteriorada e potencializam formas mais amplas de intervir em saúde (BRASIL, 2010). Educação, saúde e trabalho são práticas sociais constituintes do modo de produção da existência humana, são fenômenos transformadores das relações sociais (MOROSINI; FONSECA; PEREIRA, 2009).

Válido é sublinhar que, entre as estratégias da Política Nacional de Promoção em Saúde está o apoio a iniciativas referentes às escolas promotoras da saúde com foco, em especial, em ações de alimentação saudável; práticas corporais/atividades físicas e ambiente livre de tabaco (BRASIL, 2010). A referida Portaria reconhece a escola como um espaço propício à formação de hábitos saudáveis e à construção da cidadania. Reflexões sobre saneamento básico é outro viés fundamental para evitar doenças e oferecer melhores condições de vida e trabalho às comunidades. Daí a importância em se desen- 
volver oficinas de Educação em Saúde e Ambiente na prevenção de doenças. Zoonoses e antropozoonoses estão entre as prioridades mundiais, tendo em vista as endemias e epidemias que assolam o planeta. É preciso refletir e socializar conhecimentos sobre a relação entre as zoonoses e o saneamento, com ênfase nas medidas preventivas de doenças emergentes e reemergentes no Brasil.

As doenças zoonóticas são aquelas transmitidas dos animais para os humanos, tais como doença de Chagas, raiva, leishmanioses, leptospirose, febre amarela, dengue e malária.

As ações humanas sobre o ambiente como a urbanização, pecuária e industrialização vêm proporcionando um maior contato entre seres humanos, animais silvestres e domésticos, facilitando assim a proliferação de agentes infecciosos. Nos últimos anos, tem-se notado episódios de novas enfermidades bem como o reaparecimento de doenças datadas como erradicadas (RODRIGUES et al., 2017, p. 27).

Ainda neste escopo, o Decreto n. 6.286, de 5 de dezembro de 2007 (BRASIL, 2007b) institui o Programa Saúde na Escola (PSE), que tem como primeiro objetivo promover a saúde (e a cultura da paz), reforçando a prevenção de agravos à saúde, bem como fortalecer a relação entre as redes públicas de saúde e de educação, e a Portaria Interministerial n. 675, de 4 de junho de 2008, que institui a Comissão Intersetorial de Educação e Saúde na Escola, com a finalidade de estabelecer diretrizes da política de educação e saúde na escola, em conformidade com as políticas nacionais de educação e com os objetivos, princípios e diretrizes do Sistema Único de Saúde e tem, entre as suas competências, propor estratégias de integração e articulação entre as áreas de saúde e de educação nas três esferas do governo e apresentar referenciais conceituais de saúde necessários para a formação inicial e continuada dos profissionais de educação na esfera da Educação Básica.

\section{Destaca-se que o Programa Saúde na Escola}

implica a superação do modelo biomédico de atenção aos estudantes para uma proposta promotora de saúde, com a participação efetiva dos gestores, profissionais das Estratégias de Saúde da Família (ESFs) e da escola, e comunidade escolar (estudantes, pais, comunidade do entorno), no enfrentamento de suas necessidades específicas, proporcionando o trabalho com capacidades individuais e coletivas existentes (FERREIRA et al., 2014, p. 73).

O PSE foi constituído por cinco componentes: avaliação das condições de saúde das crianças, adolescentes e jovens que estão na escola pública; promoção da saúde e de atividades de prevenção; educação permanente e capacitação dos profissionais da educação e da saúde e de jovens; monitoramento e avaliação da saúde dos estudantes; monitoramento e avaliação do programa. Mais do que uma estratégia de integração das políticas setoriais, o PSE se propõe a ser um novo desenho da política de educação e saúde, visto que trata a saúde e educação integrais como parte de uma formação ampla para a cidadania e o usufruto pleno dos direitos humanos; permite a progressiva ampliação das ações executadas pelos sistemas de saúde e educação com vistas à atenção integral à saúde de crianças e adolescentes e promove a articulação de saberes, a participação de estudantes, pais, comunidade escolar e sociedade em geral na construção e controle social da política pública. 
Há muito a ser desenvolvido para que o Programa Saúde na Escola alcance plenamente seus objetivos. Estudos que avaliaram o funcionamento do Programa e suas ações em instituições contempladas identificaram a existência de fragilidades e limitações na articulação e integração intersetorial, bem como na instalação do PSE. A apropriação dos papéis e responsabilidades ainda não é bem caracterizada pelos sujeitos. Há um distanciamento temporal entre os documentos oficialmente instituídos e a criação de uma cultura de saúde que se viabilize no espaço educativo, além da pouca participação das equipes escolares, seja do corpo diretivo, seja dos(das) professores(as) e distância da corresponsabilização da escola na condução do Programa. Foi percebido que a saúde vai à escola ao invés de a escola promover saúde, e o conhecimento ainda repassado aos estudantes em detrimento da construção, problematização e reflexão conjunta. Os(as) professores(as), com sua pouca participação, na maioria das vezes são reprodutores(as) dos ensinamentos e das instruções da saúde. Há lacunas na capacitação para a ação (SILVA-SOBRINHO et al., 2017; SOUSA; ESPERIDIÃO; MEDINA, 2017).

A Educação em Saúde interdisciplinar somente é efetiva quando praticada por profissionais capacitados para planejar e integrar todas as áreas que agregam esta política pública. Para sua instituição é necessário não só planejamento estratégico com identificação dos problemas a serem enfrentados, das características do público, dos meios de comunicação adequados, mas também acompanhamento e avaliação (SILVA-SOBRINHO et al., 2017).

\section{CONSIDERAÇÕES FINAIS}

Assim, entendendo que professores(as) do Ensino Fundamental e Médio também devem ser protagonistas no processo de educar em saúde, sugere-se que o tema tangencie o currículo de sua formação acadêmica e que gestores oportunizem momentos para que esses profissionais possam discutir suas práticas, tanto no que se refere à metodologias ativas para educar em saúde quanto para atualizar conhecimentos sobre a saúde individual e coletiva para que, efetivamente, a escola seja um espaço de ações promotoras de saúde, como um elemento fundamental e intersetorial comprometido com as questões do escopo da saúde coletiva de suas crianças, adolescentes, jovens e comunidade em geral.

Numa perspectiva libertadora é possível desenvolver Educação em Saúde com foco no incentivo à consciência crítica, com uso de diversas metodologias que facilitem o empoderamento de cada pessoa envolvida neste processo, sejam estudantes, professores(as), profissionais de saúde e comunidade, que favoreçam a troca de experiências e estimulem a autonomia. Sendo assim, para a mudança das práticas docentes é preciso conhecer, divulgar, investigar e socializar novas formas de educar e aprender saúde e, sobretudo, mobilizar educadores(as), profissionais e gestores(as) das Secretarias Municipais para parcerias colaborativas com foco na atenção às necessidades dos estudantes, na busca da promoção de sua saúde, no sentido de fomentar a educação em saúde para além do hegemônico, ou seja, no que se refere ao conceito e práticas de saúde e de educação. 


\section{REFERÊNCIAS}

ALMEIDA FILHO, N. O que é saúde? Rio de Janeiro: Fundação Osvaldo Cruz, 2011. 160 p.

BASTOS, C. C. Metodologias ativas. 2006. Disponível em: <http://educacaoemedicina.blogspot.com. $\mathrm{br} / 2006 / 02 /$ metodologias-ativas.html>. Acesso em: $11 \mathrm{dez} .2017$.

BATISTELLA, C. Abordagens contemporâneas do conceito de saúde. In: FONSECA, A. F.; CORBO, A. D. (Org.). O território e o processo saúde-doença. Rio de Janeiro: EPSJV; Fiocruz, 2007. p. 51-86. Disponível em: <http://www.epsjv.fiocruz.br/pdtsp/index.php?id=2\&prioridade=2>. Acesso em: 11 dez. 2017.

BORGES, T. S.; ALENCAR, G. Metodologias ativas na promoção da formação crítica do estudante: o uso das metodologias ativas como recurso didático na formação crítica do estudante do ensino superior. Cairu em Revista, v. 3, n. 4, p. 119-143, 2014.

BRANDÃO, C. R. Círculo de cultura. In: STRECK, R.; D.; REDIN, E.; ZITKOSKI, J. J. (Org.). Dicionário Paulo Freire. 2. ed. rev. amp. Belo Horizonte: Autêntica Editora, 2010. p. 69-70.

BRASIL. CONFERÊNCIA NACIONAL DE SAÚDE, 8., 1986. Brasília: Ministério da Saúde, 1986.

Parâmetros curriculares nacionais: meio ambiente, saúde (1aㅡ a 4a série). Brasília: Ministério da Educação (MEC); Secretaria de Educação Fundamental (SEF), 1997.

Comissão Nacional dos Determinantes Sociais da Saúde - CNDSS. Determinantes sociais da saúde ou por que alguns grupos da população são mais saudáveis que outros? Rio de Janeiro: Fiocruz, 2006. Disponível em: <www.determinantes.fiocruz.br>. Acesso em: 20 dez. 2017.

Fundação Nacional de Saúde. Diretrizes de educação em saúde visando à promoção da saúde: documento base. Brasília: Funasa, 2007a.

Decreto no 6.286, de 5 de dezembro de 2007. Institui o Programa Saúde na Escola - PSE, e dá outras providências, Brasília: Ministério da Saúde, 2007b.

Secretaria de Atenção à Saúde. Departamento de Atenção Básica. Saúde na escola. Brasília: Ministério da Saúde, 2009.

Ministério da Saúde. Secretaria de Vigilância em Saúde. Secretaria de Atenção à Saúde. Política nacional de promoção da saúde. 3. ed. Brasília, 2010. Disponível em: <http://bvsms.saude.gov.br/bvs/ publicacoes/politica_nacional_promocao_saude_3ed.pdf>. Acesso em: 13 dez. 2017.

Ministério da Saúde. Secretaria de Vigilância em Saúde. Informação e análise epidemiológica. Objetivos e metas dos indicadores da saúde do Ministério da saúde e determinantes sociais. Disponível em: <http://svs.aids.gov.br/dantps/acesso-a-informacao/acoes-e-programas/ods/objetivos-e-metas>. Acesso em: 13 jan. 2018.

ELIAS, C. S. et al. Quando chega o fim? Uma revisão narrativa sobre terminalidade do período escolar para alunos deficientes mentais. SMAD: Revista Electrónica en Salud Mental, Alcohol y Drogas, v. 8, n. 1, p. 4853, 2012.

FERREIRA, I. R. C. et al. Percepções de gestores locais sobre a intersetorialidade no Programa Saúde na Escola. Revista Brasileira de Educação, v. 19, n. 56, 2014.

FONTANA, R. T. A vigilância sanitária no contexto escolar: um relato de experiência. Revista Brasileira de Enfermagem, v. 61, n. 1, p. 131-134, 2008.

FONTANA, R. T.; BRUM, Z. P. A educação em saúde fundamentada em Paulo Freire: uma reflexão sobre as práticas do enfermeiro. In: FÓRUM DE ESTUDOS LEITURAS PAULO FREIRE, 16., 2014, Santo Ângelo. Anais... Santo Ângelo: Universidade Regional Integrada do Alto Uruguai e das Missões; Campus de Santo Ângelo, 2014.

GUSTAVO, L. S.; GALIETA, T. A educação em saúde está contemplada na formação inicial de professores de Ciências Biológicas? Revista da SBEnBio - Associação Brasileira de Ensino de Biologia, n. 7, p. 4.8774.889, 2014.

LEITE, C.T. et al. Prática de Educação em Saúde percebida por escolares. Cogitare Enfermagem, v. 19, n. 1, p. 13-19, 2014.

LIMA, D. F.; MALACARNE, V.; STRIEDER, D. M. O papel da escola na promoção da saúde: uma mediação necessária. Eccos Revista Científica, n. 28, p. 191-206, 2012.

MACHADO, A. G. M.; WANDERLEY, L. C. S. Educação em saúde. Unifesp/Unasus. Disponível em: <http:// www.unasus.unifesp.br/biblioteca_virtual/esf/2/unidades_conteudos/unidade09/unidade09.pdf>. Acesso em: 20 maio 2017 
MAIA, E. R. et al. Validação de metodologias ativas de ensino-aprendizagem na promoção da saúde alimentar infantil. Revista Nutrição, v. 25, n. 1, p. 79-88, 2012.

MARUXO, H. B. et al. Webquest e história em quadrinhos na formação de recursos humanos em Enfermagem. Revista da Escola de Enfermagem da USP, v. 49, especial 2, p. 68-74, 2015.

MESSINA, G. Estudio sobre el estado da arte de la investigación acerca de la formación docente en los noventa. Trabalho apresentado à Reunión de Consulta Técnica sobre investigación en Formación del Profesorado, Organización de Estados Ibero-Americanos para la Educación, la Ciência y la Cultura, México, 1998.

MOHR, A.; SCHALL, V. T. Rumos da educação em saúde no Brasil e sua relação com a educação ambiental. Cadernos de Saúde Pública, v. 8, n. 2, p. 199-203, 1992.

MOROSINI, M. V.; FONSECA, A. F.; PEREIRA, I. B. Educação em saúde. Dicionário de educação profissional em saúde, 2009. Disponível em: <http://www.epsjv.fiocruz.br/dicionario/verbetes/edusau.html>. Acesso em: 2 maio 2017.

MOTA, A. S. et al. Fracasso escolar no ensino fundamental: de quem é a culpa. 2008. Disponível em: $<$ file:///C:/Users/Rosane/Desktop/FRACASSO-ESCOLAR-NO-ENSINO-FUNDAMENTAL-12-12-08.pdf>. Acesso em: 20 dez. 2017.

ORGANIZAÇÃO MUNDIAL DE SAÚDE (OMS). Conceito de saúde segundo OMS/WHO, 2016. Disponível em: <http://cemi.com.pt/2016/03/04/conceito-de-saude-segundo-oms-who>. Acesso em: 20 dez. 2017.

ROCHA, E. A. C. A pesquisa em Educação Infantil no Brasil: trajetória recente e perspectiva de consolidação de uma pedagogia da educação infantil. Florianópolis: UFSC; Centro de Ciências da Educação, Núcleo de Publicações, 1999.

RODRIGUES et al. Desafios da saúde pública no Brasil: relação entre zoonoses e saneamento. Scire Salutis, v. 7, n. 1, p. 27-37, 2017.

SANTOS, A. V.; FONTANA, R. T. F; BRUM, Z. P. Health education as a strategy for healthy sexuality. Revista de Pesquisa: Cuidado é Fundamental, v. 5, n. 4, p. 529-536, 2013.

SHIRATORI, K. et al. Educação em saúde como estratégia para garantir a dignidade da pessoa humana. Revista Brasileira de Enfermagem, v. 57, n. 5, p. 617-619, 2004.

SILVA, R. P. N. et al. Concepções de professores sobre os processos de educação em saúde no contexto escolar. Contexto \& Educação Editora Unijuí, ano 32, n. 10, 2017.

SILVA, K. V. L. G. et al. Formação de adolescentes multiplicadores na perspectiva das competências da promoção da saúde. Revista Brasileira de Enfermagem, v. 71, n. 1, p. 89-96, 2018.

SILVA, C. S.; BODSTEIN, R. C. A. Referencial teórico sobre práticas intersetoriais em promoção da saúde na escola. Ciência \& Saúde Coletiva, v. 21, n. 6, p. 1.777-1.788, 2016.

SILVA-SOBRINHO, R. A. et al. Percepção dos profissionais da educação e saúde sobre o programa saúde na escola. Revista Pesquisa Qualitativa, São Paulo. SP, v. 5, n. 7, p. 93-108, 2017.

SOUSA, M. C.; ESPERIDIÃO, M. A.; MEDINA, M. G. A intersetorialidade no Programa Saúde na Escola: avaliação do processo político-gerencial e das práticas de trabalho. Ciência \& Saúde Coletiva, v. 22, n. 6, p. 1.781-1.790, 2017.

SOUZA, I. P. M.; JACOBINA, R. R. Educação em saúde e suas versões na história brasileira. Revista Baiana de Saúde Pública, v. 33, n. 4, 2009.

UNITED NATIONS CHILDREN'S FUND (Unicef). Competências para a vida trilhando caminhos de cidadania. Brasília, DF, 2012. Disponível em: <https://www.unicef.org/brazil/pt/br_competencias_para_a_vida.pdf >. Acesso em: 20 dez. 2016.

UNIVERSIDADE DE SÃO PAULO. Biblioteca Paulo de Carvalho Matos. Tipos de revisão da literatura. 2015. Disponível em: <http://www.fca.unesp.br/Home/Biblioteca/tipos-de-evisao-de-literatura.pdf>. Acesso em: 13 dez. 2017.

VOSGERAU, D. S. R.; ROMANOWSKI, J. P. Estudos de revisão: implicações conceituais e metodológicas. Rev. Diálogo Educ., Curitiba, v. 14, n. 41, p. 165-189, jan./abr. 2014.

WEGNER, W. et al. Educação para cultura da segurança do paciente: implicações para a formação profissional. Escola Anna Nery, v. 20, n. 3, 2016. Disponível em: <http://www.scielo.br/pdf/ean/v20n3/ 1414-8145-ean-20-03-20160068.pdf>. Acesso em: 20 dez. 2017. 